\title{
De la comunicación institucional a las fake news
}

Samia Benaissa Pedriza | samia.benaissa@ucm.es Universidad Complutense de Madrid

\section{Libro:}

Menéndez, M. A; Peiro, L.; Berbell, C.; Serrano Martínez, J. De la comunicación institucional a las fake news (2018). El Ángel. Gijón, 102 pp. ISBN: 9788494780431

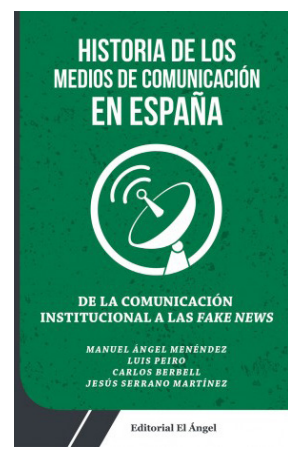

\section{Cómo citar este texto:}

Samia Benaissa Pedriza (2018) De la comunicación institucional a las fake news. Miguel Hernández Communication Journal, 9 (2), pp. 543 a 548. Universidad Miguel Hernández, UMH (Elche-Alicante). DOI: http://dx.doi.org/10.21134/mhcj.v0i9.266

\section{How to cite this text:}

Samia Benaissa Pedriza (2018) From institutional communication to fake news. Miguel Hernández Communication Journal, 9 (2), pp. 543 a 548. Universidad Miguel Hernández, UMH (Elche-Alicante). DOI: http://dx.doi.org/10.21134/mhcj.v0i9.266 
La proliferación de noticias falsas -o fake news- en un ecosistema informativo saturado por una miríada de actores no profesionales no solo perjudica los intereses de los medios de comunicación. Las instituciones de los tres poderes del Estado, -legislativo, ejecutivo y judicial-, así como los partidos políticos de las sociedades desarrolladas también deben hacer frente a la desinformación y a la manipulación informativa practicada por oscuros núcleos de poder. A menudo, estas instancias interesadas y partidistas buscan desestabilizar un sistema de información fundado sobre unas bases democráticas, que genera entre sus ciudadanos opiniones informadas y no desinformadas.

En ese contexto se publica el ensayo De la comunicación institucional a las fake news, una obra coordinada por el periodista Manuel Ángel Menéndez, y en la que participan los también profesionales de la información Luis Peiro y Carlos Berbell, así como Jesús Serrano Martínez, jefe del departamento de prensa del Congreso de los Diputados. El objetivo de esta obra colectiva, en palabras de su coordinador es "descubrir cómo es la comunicación institucional en la era de la revolución tecnológica y los peligros de la posverdad y las fake news".

Mediante el estudio de casos y un ejercicio de observación participante de los propios autores a lo largo de sus respectivas carreras profesionales, se efectúa un repaso en cuatro capítulos del estado de la comunicación política e institucional en España durante las dos últimas décadas.

Manuel Ángel Menéndez advierte de los peligros de la tecnología cuando esta es usada como instrumento de manipulación informativa. El autor sitúa los antecedentes de esta práctica en las "guerras de guerrillas" que tuvieron lugar durante la guerra de Irak y la campaña de las elecciones generales de 2004 en España. En aquellos momentos la estrategia se ideó por partidos políticos pequeños y con escasos medios económicos que irrumpieron masivamente en los espacios informativos tradicionales con tácticas basadas en relaciones de proximidad. Aunque fue el desarrollo de Internet el factor que más influyó en la manera de comunicar mensajes políticos, ya que, a juicio de Menéndez, fueron los SMS, el Messenger y las pujantes redes sociales los que más contribuyeron a la formación de los resultados electorales de 2004.

El efecto "bola de nieve" provocado por la información mil veces difundida y repetida en las redes sociales también se da en otro caso reciente analizado por el experto comunicador: la injerencia rusa en el referéndum independentista catalán votado el 1 de octubre de 2017. Menéndez cita un estudio dirigido por el español Javier Lesaca y llevado a cabo desde la Universidad George Washington que demuestra que dos medios rusos (RT y Sputnik) lograron que la información partidista y manipulada que enlazaban se compartiera más que la difundida por medios públicos españoles como Efe y RTVE o internacionales como The Guardian y CNN. Gracias a los flujos de información masivos generados por cuentas falsas los medios rusos lograron que los algoritmos 
de las plataformas y redes sociales más utilizadas por los usuarios les dedicasen un lugar destacado. Menéndez también alude a los efectos perniciosos de las noticias falsas en los resultados del Brexit o en la elección de Donald Trump como presidente de Estados Unidos. Una postura que sostiene un buen número de expertos pero que también matizan otros como Brendan Nyhan, profesor de ciencia política en el Darmouth Collegue. Según Nyhan, los bots rusos tuitearon 2,1 millones de veces en los días previos a la celebración de las elecciones presidenciales norteamericanas, una cantidad preocupante pero que solo representó un $1 \%$ de todos los tuits relacionados con las elecciones.

Luis Peiro, exdirector de la revista Cambio 16 y responsable de prensa en el Ministerio del Interior durante el último gobierno de Felipe González, analiza la comunicación institucional desde el punto de vista del poder ejecutivo. Para el autor, uno de los principales problemas que surgen en este ámbito es evitar las filtraciones de información sensible a la prensa. El autor enlaza presente y pasado mediante dos ejemplos ilustrativos: las filtraciones de los Papeles de Panamá (por las que el Consorcio de Periodistas de Investigación obtuvo el Premio Pulitzer en el año 2017) y las que se produjeron en el caso GAL durante la guerra sucia contra el terrorismo en los años ochenta.

Según Peiro, la amenaza que constituyen las noticias falsas es especialmente grave en el caso de la información difundida públicamente por el Ministerio del Interior, ya que a menudo se comparten imágenes de sujetos en situación de vulnerabilidad (menores de edad, ancianos, personas heridas, etc.) que pueden ser fácilmente manipulables gráficamente. Algo que ocurrió efectivamente durante el tratamiento informativo de la jornada electoral ilegal del 1 de octubre de 2017 en Cataluña. Según los expertos en ciberseguridad del gobierno español, el 50\% de los perfiles que difundieron noticias falsas sobre el proceso catalán procedían de servidores rusos. Muchas de las fotografías que ilustraban las noticias no se correspondían con la realidad de los hechos y los protagonistas de aquella jornada (imágenes de heridos, cargas policiales pertenecientes a acontecimientos informativos ajenos).

El autor lamenta asimismo las dificultades de los medios de comunicación tradicionales para contrastar con eficacia las noticias que difunden, lo que está ocasionando una gran desconfianza tanto en los medios privados como en los públicos. Y es que los medios, en ocasiones "caen en la tentación de rebotar acríticamente sus contenidos", lo que da lugar a la publicación de noticias falsas en espacios que hasta el momento gozaban de toda credibilidad. En la misma línea que Peiro se expresa críticamente el periodista Jordi Évole en el prólogo "El (mal) estado de la información" del ensayo de Marc Amorós, Fake news, la verdad de las noticias falsas (2018): "los intereses de cada medio, la falta de recursos en las redacciones y la dictadura del clic, han llevado a la profesión a relajar el rigor, el contraste de las noticias". 
Peiro observa que el peligro de la desinformación es tan serio que en 2018 el gobierno español incluyó a las campañas de desinformación en la lista de las principales amenazas a la seguridad nacional. También en ese sentido parece que la Unión Europea está dedicando más fondos a combatir el problema a nivel comunitario.

La comunicación de los asuntos de justicia es abordada por Carlos Bertell, exdirector del primer canal de juicios en televisión de Europa y actual director del diario digital Confilegal, especializado en información judicial. Bertell lamenta la dirección hacia la que ha girado el ejercicio de la profesión periodística, tanto en medios privados como en los gabinetes de comunicación de ministerios y organismos públicos. Frente a los periodistas que salían a la calle en busca de noticias hace tan solo un par de décadas, se encuentran ahora profesionales que dependen en exceso de las nuevas tecnologías para realizar su trabajo. La estandarización de las prácticas profesionales nos está llevando, según Bertell, a una saturación informativa provocada por demasiados medios cubriendo simultáneamente la misma información.

Tomando como base los datos del Consejo General del Poder Judicial, Bertell ofrece una panorámica de la situación en que se encuentra la comunicación de los asuntos relativos a la justicia en España y advierte de la necesidad de modificar el actual modelo de relaciones entre los profesionales de la información y los representantes institucionales. Este modelo debería dar paso a otro más accesible y divulgativo, centrado en desarrollar de forma directa las relaciones entre la Administración de Justicia y los propios ciudadanos.

Tomando en consideración esta propuesta, se podría señalar en la misma línea de pensamiento que el autor, que el Plan 2018 de Publicidad y Comunicación Institucional del gobierno español incluye medidas específicas sobre campañas que se desarrollarán en cada uno de los ministerios. En lo que respecta al Ministerio de Justicia, se ha destinado medio millón de euros a varias campañas de sensibilización y difusión de información dirigidas a ciudadanos y a empresas.

Por último, Jesús Serrano Martínez analiza la relación entre la comunicación del poder legislativo y las nuevas tecnologías de la información. Durante los últimos años, el Congreso de los Diputados, institución bien conocida por el autor, está llevando a cabo un proceso de modernización tecnológica con el fin de acercar a los ciudadanos la información generada por los distintos grupos políticos que la conforman, así como la organizada por los propios servicios de la Cámara Baja. Así, se menciona la existencia del Canal Parlamentario, creado para dar a conocer al público la actividad parlamentaria (sesiones plenarias, de comisiones y actos públicos de la cámara), y de un circuito cerrado de televisión que emite de forma simultánea y en directo todas las actividades 
del Parlamento. Ambas iniciativas se incluyen en un plan de modernización de la institución que incluye además la digitalización del archivo audiovisual, que es accesible para cualquier ciudadano interesado.

El autor concluye que la administración parlamentaria española es una administración "innovadora y abierta gracias a la introducción de las nuevas tecnologías".

De la comunicación institucional a las fake news constituye un apreciable ejercicio de divulgación sobre la evolución de la comunicación política e institucional en España durante su historia más reciente. Los cambios político-sociales y tecnológicos introducidos a partir de la llegada del nuevo milenio justifican la elaboración de una retrospectiva tan estimable como la que se presenta en este trabajo. Se trata de una obra cuyo valor principal reside en las aportaciones personales de sus autores, experimentados comunicadores y expertos en comunicación institucional. Las conclusiones a las que estos llegan refuerzan la necesidad de luchar con la mayor intensidad y desde todos los frentes (sector privado, público e institucional) contra situaciones actuales de desinformación y manipulación informativa que recuerdan demasiado a conflictos informativos del pasado, hace tiempo superados.

El uso de tácticas propagandísticas no es nuevo, aunque sí es excepcional su irradiación en sistemas informativos sustentados en principios democráticos y ampliamente consolidados. El uso interesado de instrumentos tecnológicos que facilitan la difusión masiva de noticias falsas solo puede ser neutralizado mediante la instauración de modelos de comunicación eficaces que refuercen la confianza de los ciudadanos en sus instituciones y en sus medios de comunicación social.

\section{Referencias}

Amorós García, M. (2018). Fake news: la verdad de las noticias falsas. Prólogo de Jordi Évole. Barcelona: Plataforma editorial. 192 páginas. ISBN: 978-8417114725

Nyahn, B. (2018). El verdadero efecto politico de las noticias falsas. The New York Times. 16 de febrero de 2018. [https://www.nytimes.com/es/2018/02/16/efecto-politico-noticias-falsas/]. [Consultado 15 de junio 2018]

Gobierno de España. Plan de Publicidad y Comunicación Institucional 2018. hhttp://www. lamoncloa.gob.es/serviciosdeprensa/cpci/Documents/Plan2018.pdf] [Consultado 15 de junio 2018] 
MHCJ no 9 (2) | Año 2018 - Reseña no 4 (6) - Páginas 543 a 548 - mhjournal.org

\section{(c) (†)}

Licencia Creative Commons

Miguel Hernández Communication Journal

mhjournal.org

\section{Cómo citar este texto:}

Samia Benaissa Pedriza (2018) De la comunicación institucional a las fake news. Miguel Hernández

Communication Journal, 9 (2), pp. 543 a 548. Universidad Miguel Hernández, UMH (Elche-Alicante). DOI: http://dx.doi.org/10.21134/mhcj.v0i9.266 